\title{
STUDIES ON THE CHICKEN EYE PROPERTIES EXPOSED TO ARGON LASER BY DIELECTRIC METHODS
}

\author{
E.M. EL SAYED, M.S. TALAAT and S.M. SALLAM* \\ Physics Department, Faculty of Science, Ain Shams University, Cairo, Egypt \\ *Physics Department, Faculty of Science, Zagazig University, Benha, Egypt
}

\begin{abstract}
Argon Laser is commonly used now as a powerful tool in the human eye operations. On the other hand, the exposure of the eye to laser, in the visible range, may cause many alterations in the retinal structure.

The aim of the present work is to study the structural variations in the eye caused by argon laser exposure, of the same intensity and duration as that used in medical treatments and at different temperatures of 10,20 , and $30^{\circ} \mathrm{C}$, by dielectric measurements. These measurements were carried out immediately after laser exposure and after a certain period ( 1 - 5 days) needed for the recovery processes.

The results of the experiments showed that the impedance components $\left(Z_{R}\right.$ and $\left.Z_{L}\right)$ and the dielectric loss $\left(\epsilon^{\prime \prime}\right)$ changed with temperature and after eye exposure to $1 \mathrm{~mW} / \mathrm{cm}^{2}$ argon laser of duration $0.12 \mathrm{sec}$. The dielectric loss, $\in$ ", increased immediately after laser exposure and then decreased during the recovery periods indicating a repairing process after laser treatments in the fourth or fifth day which is greatly significant at a temperature of $10^{\circ} \mathrm{C}$.

The exact reactive mechanism of laser effects on the eye is still not really understood. These effects may be due to vasodillation of blood vessels of the retina which is accompanied by an increase in blood capillary permeability. This increase in permeability permits larger serum proteins to inter the cells, shifting the osmotic pressure at the capillary wall such that cell swelling takes place due to water entrance. The repairing processes occurred due to that some intracellular substances are released and gradually diffused out of the cells and this would explain the latent period of several days.

Based on the results of the present work, we may conclude that, in order to decrease the damage/repair ratio, it is preferable to place the dark adapted patient's eye at low temperature during the laser exposure.
\end{abstract}

\section{1.- Introduction}

The use of dielectric measurements as a tool for studying molecular and cellular parameters is a well established technique of continuing importance /1/. Several biophysical studies have been provided by using the dielectric measurements. Quantitative details of the molecular size, shape and extent of hydration of protein molecules were reported by Oncley, 1943,/2/, Haggis et al., 1951,/3/, Grant, 1965,/4/, and Schwan, 1965,/5/. Measurements of the diffusional motion of proteins and lipids in cell membrane were carried out by Kell and Harris, 1985,/6/, Zimmermann, 1982,/7/, Arnold et al., 1985,/8/. Fuhr et al., 1985, 1986,/9/, /10/, 
studied the influence of hydration on enzyme activity while intramolecular mobility, protonic and ionic charge transport studies in protein were reported by Bone and Pethig, 1983,/11/, Neumann, 1986,/12/, and Morgan and Pethig, 1986,/13/.

The dielectric permittivity of biological tissues typically decreases with increasing frequency in three steps (i.e. dispersions) which are designated $\alpha, \beta$ and $\gamma$ dispersions (Schwan, $1957, / 14 /)$. But, for technical reasons with the measurements of very small phase angles in the presence of potentially large artifacts due to the electrode polarization (Kell, 1986b), $/ 15 /$, rather little work has been reported, concerning the dielectric properties of tissues in the frequency range up to a few $\mathrm{KHz}$. So far, accurate data on the dielectric properties of tissues, at radio frequencies (RF) are needed for evaluation of the possible health hazards of non-ionizing radiation, and for the design and evaluation of equipment for therapeutic or diagnostic application of this energy.

In view of the interest in the biological effects of RF and microwave within the eye, and therefore in the dielectric properties of the eye tissues upon which such effects depend, we decided to measure the impedance components $\left(Z_{R}\right.$ and $\left.Z_{\mathrm{T}}\right)$ and dielectric loss of the eye before and after treatments, especially, those used laser for retinal photocoagulation. The aim of this work is to test the functional state of the eye exposed to laser beam, of the same intensity and duration as that used in eye photocoagulation, by the use of dielectric method. We had tried to adapt the physical conditions surrounding the exposed eye in order to minimize the side effects during the laser exposure.

\section{2.- Materials and Method}

The experiments were performed on light and dark adapted eyes of chicken, 15-20 days old. In vivo conditions, the eyes were exposed to argon laser of wavelength $488 \mathrm{~nm}$, intensity $1 \mathrm{~mW} / \mathrm{cm}^{2}$ and duration of $0.12 \mathrm{sec}$. This laser exposure conditions are similar to those used in retinal photocoagulation. The bird was then either immediately decapitated or left for several days in order to study the expected repair mechanisms (recovery periods). After bird decapitation, the eyes were then enucleated, moistened with Ringer's solution and placed in the dielectric cell. This cell consists of two parallel silver disc electrodes, $0.5 \mathrm{~cm}$ diameter coated by nonpolarizable silver chloride layer. The electrodes are mounted in a Lucite cylinder of slightly larger internal diameter. The active electrode was directly mounted on the active terminal of the impedance bridge, whilst the reference (grounded) electrode was supported by a holder mechanism to allow adjustment and accurate measurements of the inter-electrode distance. Control of the sample temperature was achieved by passing water from a thermostatically regulated bath through a water jacket coaxially surrounding the sample cell. The silver electrodes were frequently covered with silver chloride to reduce the electrode polarization artifacts to negligible levels as judged from measurements on physiological saline and other similar electrolyte solutions. The dielectric parameters were measured by using a Siemens impedance bridge (model BM 507) in the frequency range of $0.5-50 \mathrm{KHz}$.

The data of impedance, from the bridge, was firstly corrected for the series impedance measured according to Schwan's method (1963),/16/. Using the cell constant, calculated from the dimensions of the sample cell and from the previously measured value of the stray capacitance in the cell, the sample dielectric loss values were then calculated. 


\section{3.- Results}

The experiments were performed on both light and dark adapted chicken eyes at different temperatures $\left(10,20\right.$ and $\left.30^{\circ} \mathrm{C}\right)$ after exposing the bird to argon laser with the above mentioned conditions.

The impedance (real and imaginary parts $\mathrm{Z}_{\mathrm{R}}$ and $\mathrm{Z}_{\mathrm{l}}$ respectively), and the dielectric loss $(E ")$ were measured before, immediately and after five recovery days of laser exposure. The obtained data indicated that the variations of these parameters, in case of light and dark adaptation, showed approximately a similar behaviour towards laser exposure, whereas they were more regular in the later case than in the former one. So, in this work, we restrict our attention on the dark adapted results and then try to investigate the main differences between the conditions of adaptation.

Figure ( $1 \mathrm{a}, \mathrm{b}$ and $\mathrm{c}$ ) shows three sets of semicircles demonstrating the relation between $Z_{R}$ and $Z_{1}$ of dark adapted chicken eyes before and after laser exposure at fixed temperature of 10,20 and $30^{\circ} \mathrm{C}$. Each set of semicircles represents the obtained results in case of unexposed eye and those exposed immediately and after five recovery days at which the exposed bird was living in a dim light before decapitation. Each point represents the mean value calculated from five experiments and has a standard deviation less than 0.05 . The obtained results of figure (1) indicated pronounced variations of $Z_{R}$ and $Z_{Y}$, in the frequency range of $0.5-50$ $\mathrm{KHz}$, with respect to temperature in the five recovery days, especially at $10^{\circ} \mathrm{C}$. There is also the angles $\theta$ (as defined by Cole and Cole, 1941), /17/, shown in figure (1), which varied during the immediate and the five recovery days for each of the used temperatures. Their values changed at the first recovery days and then approached the normal value in the fourth or fifth ones. This can be used as an indicator for the repairing processes after laser exposure. Based on the above obtained impedance values, figures $(2 \mathrm{a}, \mathrm{b}$ and $\mathrm{c}$ ) have been constructed. They represent the relation between the dielectric loss $\in$ " and the logarithmic values of the frequency (up to $50 \mathrm{KHz}$ ) for dark adapted chicken eyes before and after the immediate and the fourth day of laser exposure at temperatures of 10,20 and $30^{\circ} \mathrm{C}(\mathrm{a}, \mathrm{b}$ and c respectively). These days have been chosen because the repairing processes began to reach a certain rate in the fourth day in comparison with the immediate and first days of recovery. These figures indicated that all the demonstrated curves have the same behaviour, while the great value of the maximum dielectric $\operatorname{loss}\left(\in_{\max }^{\prime \prime}\right)$ occurs at the frequency range of $900-2000 \mathrm{~Hz}$, which increased in the immediate exposure and then decreased in the fourth recovery day. The results showed also that $\epsilon^{\prime \prime}$ varies with the temperature reaching maximum value at $30^{\circ} \mathrm{C}$ in the immediate day of exposure.

For good illustration of the expected recovery of the dark adapted eyes, after laser exposure, the variation of the maximum dielectric loss $\epsilon_{\max }^{\prime \prime}$ in the immediate and the five recovery days are represented in figure (3), at temperatures of 10,20 and $30^{\circ} \mathrm{C}$. It is clear from this figure that $\Theta_{\max }^{\prime \prime}$ drastically decreases with respect to its normal value, with the days after exposure, but it increases again in the fourth recovery day. This indicates an increase in the repairing processes which could take place to overcome the effect produced by the laser beam. On the other hand, by regarding the effect of temperature, the figure indicated that the variations of $\epsilon_{\max }^{\prime \prime}$ at $10^{\circ} \mathrm{C}$ were less than those occurred at 20 and $30^{\circ} \mathrm{C}$ so that we may expect that this temperature is more suitable in decreasing the laser damage and hence in decreasing the time for complete recovery. 


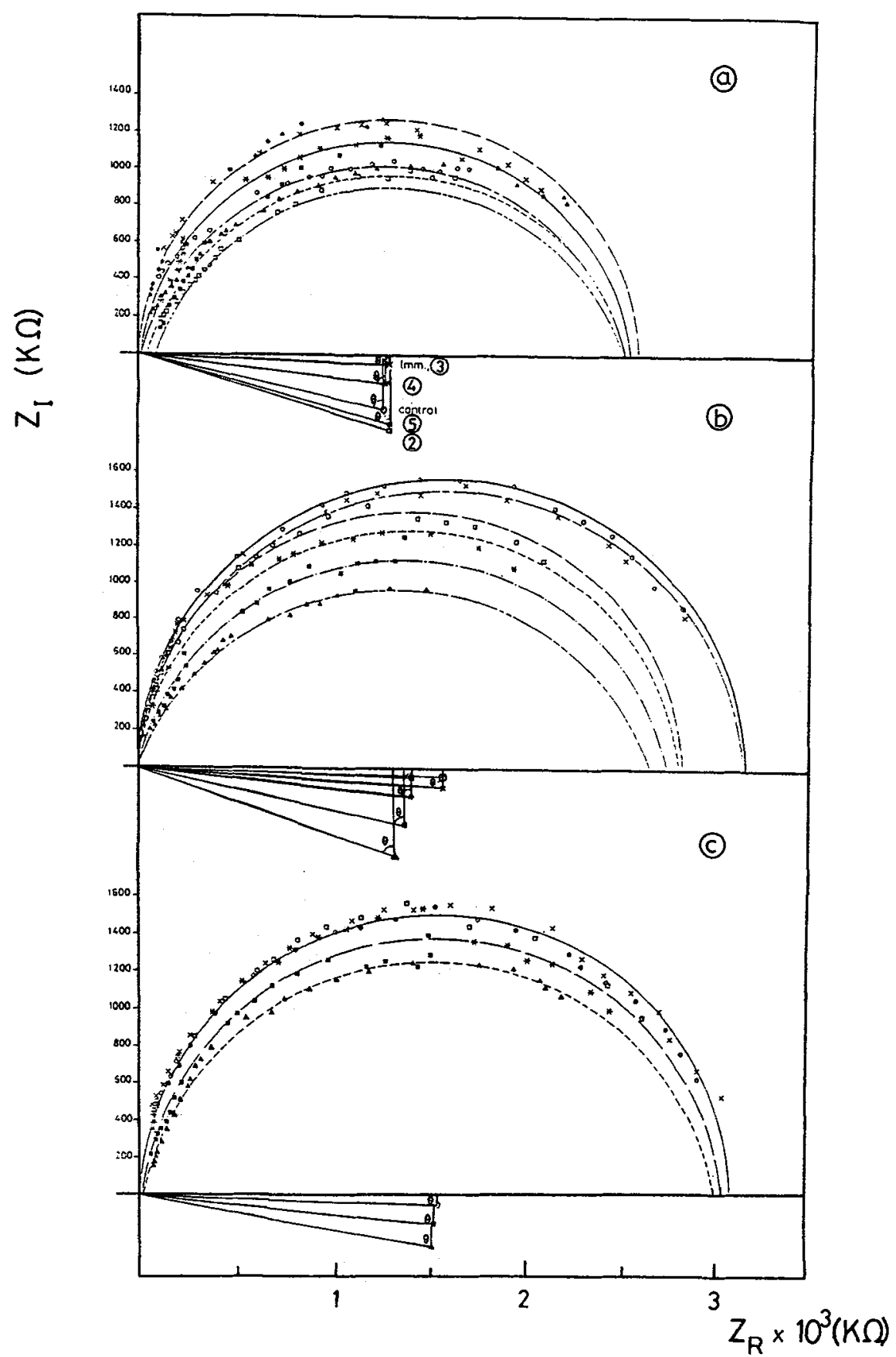

Fig.1. The relation between the real $\left(Z_{R}\right)$ and imaginary $\left(Z_{1}\right)$ parts of the chicken dark adapted eye impedance at temperatures $10^{\circ} \mathrm{C}(\mathrm{a}), 20^{\circ} \mathrm{C}(\mathrm{b})$ and $30^{\circ} \mathrm{C}$ (c) exposed to laser beam of duration $0.12 \mathrm{sec}$, immediately and for five recovery days. (control (N) $\odot$, Immediately $x, 1$ st day $\Delta, 2$ nd day $\square, 3$ rd day $\bullet, 4$ th day $*$ and 5 th day $\square$ ). 


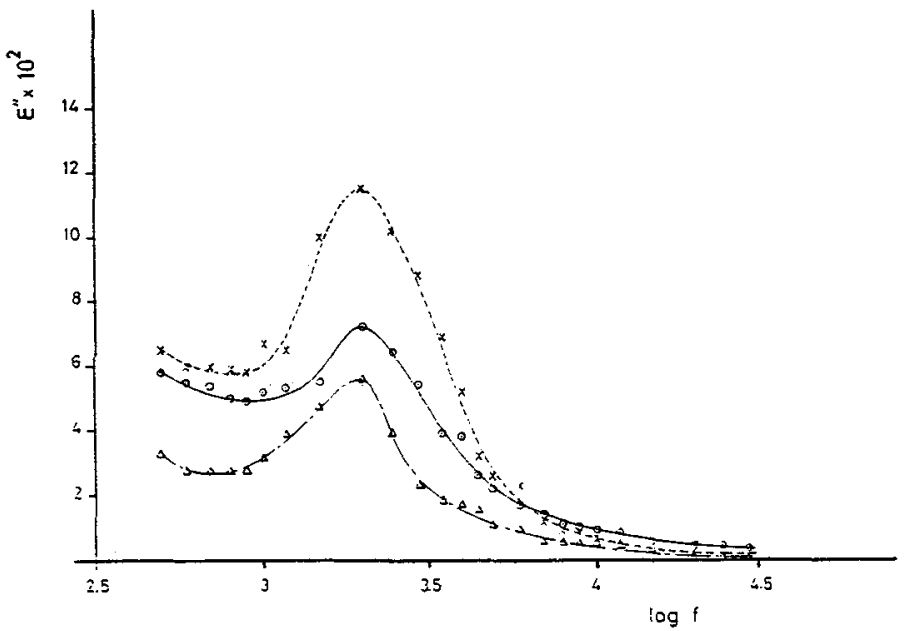

Fig.2a. The relation between the dielectric loss $\left(\epsilon^{\prime \prime}\right)$ and the logarithm of frequency $(\log f)$ of dark adapted chicken eye at a fixed temperature of $10^{\circ} \mathrm{C}$ for control $(\odot)$, immediately $(x)$ and the 4 th recovery day $(\Delta)$.

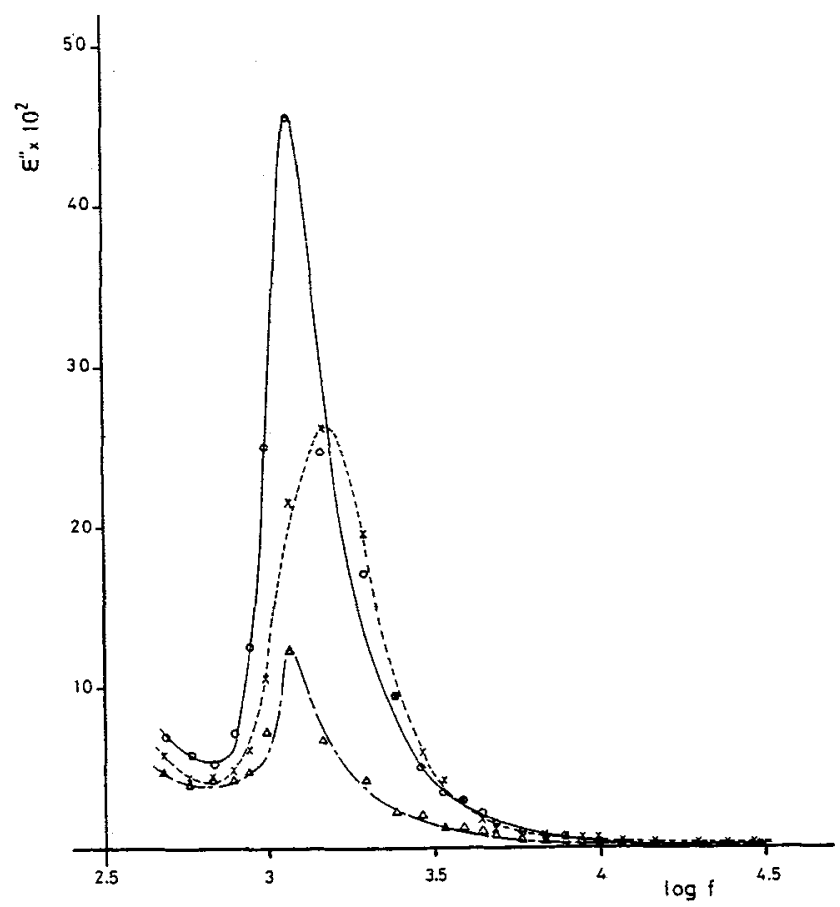

Fig.2b. The relation between the dielectric loss $\left(\epsilon^{\prime \prime}\right)$ and the logarithm of frequency $(\log f)$ of dark adapted chicken eye at a fixed temperature of $20^{\circ} \mathrm{C}$ for control $(\odot)$, immediately $(x)$ and the 4 th recovery day $(\Delta)$. 


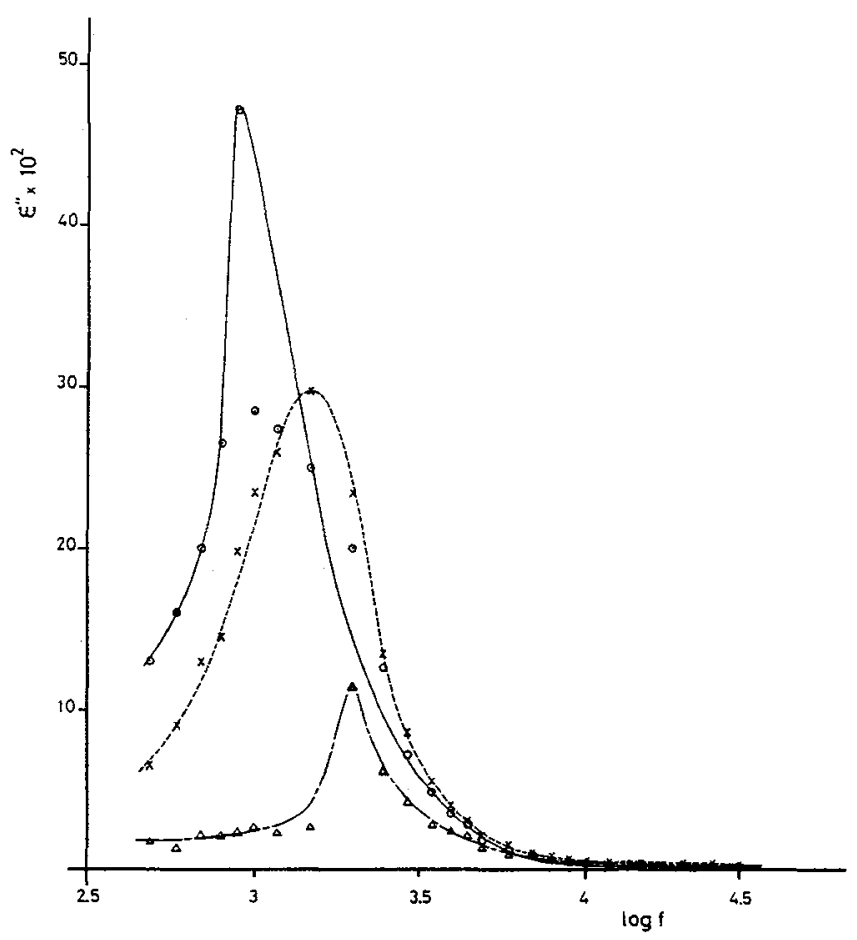

Fig.2c. The relation between the dielectric loss $\left(\epsilon^{\prime \prime}\right)$ and the logarithm of frequency $(\log f)$ of dark adapted chicken eye at a fixed temperature of $30^{\circ} \mathrm{C}$ for control $(\odot)$, immediately $(x)$ and the 4 th recovery day $(\Delta)$.

Now, in order to compare between the effects of laser eye exposure in both cases of adaptations (dark and light), the same, above mentioned, experiments were repeated on light adapted eyes. Figure (4) illustrates the relation between $\in_{\max }^{\prime \prime}$ and the recovery days after laser exposure at different temperatures $\left(10,20\right.$ and $\left.30^{\circ} \mathrm{C}\right)$. The results of figure (4) are compared with their correspondence, of dark adapted eyes, of figure (3). It is clear that the variations in $\epsilon_{\max }^{\prime \prime}$, in the five recovery days, and so, the repairing processes, in case of dark adaptation, are more regular than those in case of light adaptation. Generally, the processes of recovery are more pronounced in case of dark adaptation at a temperature of $10^{\circ} \mathrm{C}$ and in the fifth day after laser exposure.

\section{4.- Discussion.}

The dielectric parameters of normal dark adapted chicken eyes, placed at different temperatures, showed regular variations than those of the corresponding light adapted ones. This can be easily shown in figure (5) which illustrates the relation between the natural logarithm of the relaxation time $(\ln \tau)$ and the reciprocal of temperature $(1 / T)$. It represents two approximate parallel straight lines, one for each case of adaptation. 


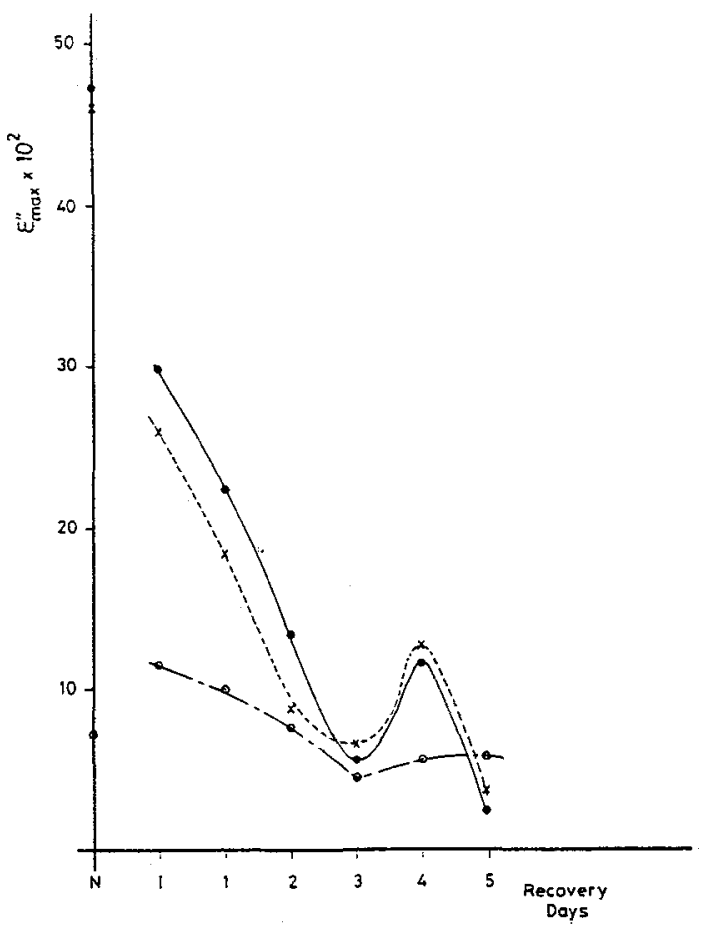

Fig.3. The relation between the maximum dielectric loss $\left(\epsilon_{\max }^{\prime \prime}\right)$ and recovery days of dark adapted chicken eye at fixed temperatures of $10^{\circ} \mathrm{C}, 20^{\circ} \mathrm{C}$ and $30^{\circ} \mathrm{C}\left(\odot-10^{\circ} \mathrm{C}, \mathrm{x}-20^{\circ} \mathrm{C}\right.$ and $\left.\Delta-30^{\circ} \mathrm{C}\right)$.

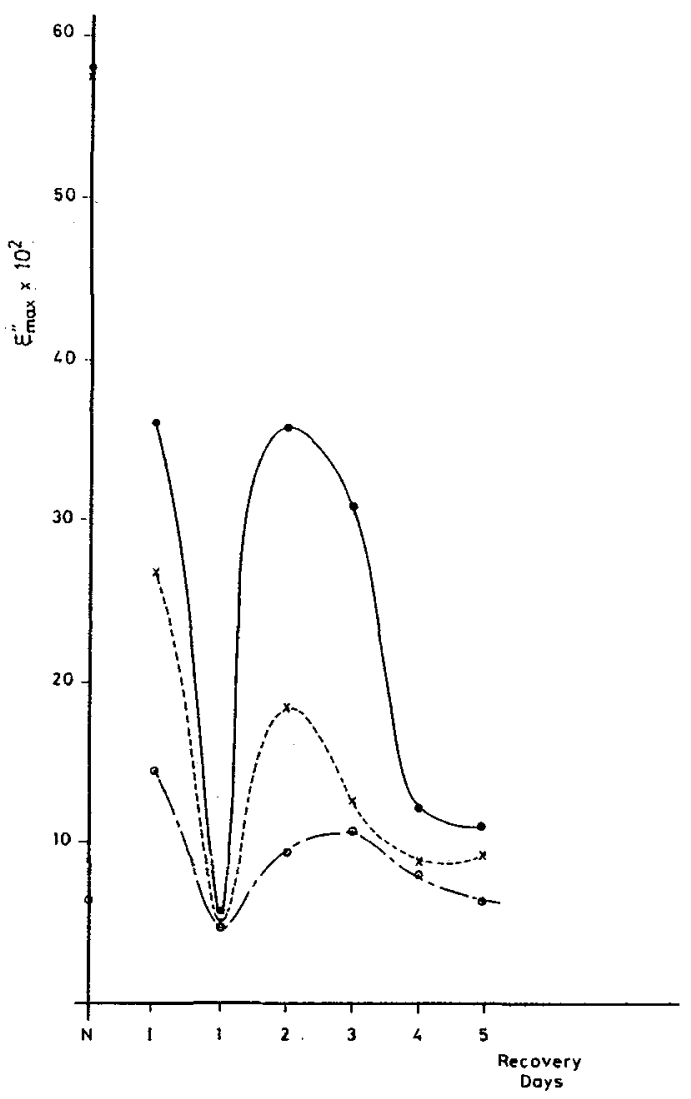

Fig.4. The relation between the maximum dielectric loss $\left(\epsilon_{\max }^{\prime \prime}\right)$ and recovery days of light adapted chicken eye at fixed temperatures of $10^{\circ} \mathrm{C}, 20^{\circ} \mathrm{C}$ and $30^{\circ} \mathrm{C}\left(\odot-10^{\circ} \mathrm{C}, \mathrm{x}-20^{\circ} \mathrm{C}\right.$ and $\left.\Delta-30^{\circ} \mathrm{C}\right)$.

According to Eyring (Glasstone et al., 1941)/18/, the relation $\ln \tau-1 / \mathrm{T}$ can be represented by

$$
\frac{1}{\tau}=\frac{\mathrm{KT}}{\mathrm{h}} \mathrm{e}^{-\mathrm{DF} / \mathrm{RT}}
$$

where $\Delta \mathrm{F}$ is the molar free energy of activation and the other symbols have their usual meanings. $\Delta F$ can be given from thermodynamic considerations by $\Delta F=\Delta H-T \Delta S$ where $\Delta S$ is the entropy of activation and $\Delta \mathrm{H}$ is the enthalpy. Then, the straight lines of figure (5) have a slope provides $\Delta \mathrm{H}$ and two interceptions indicated two values for $\Delta \mathrm{S}$. As shown in figure (5), the value of $\Delta S$ which describes the local disorder is more pronounced in case of light adaptation than that in the dark adapted one. This finding is in good agreement with the principles of photosensation and also proves the sensitivity of the used method of measurements. 
After laser exposure, the decrease in the values of $\in_{\max }^{\prime \prime}$ in the first days after exposure and the consequence increase of it during the fifth recovery day could be discussed as an increase and decrease on the retinal cell membrane permeabilities respectively. Also, it could be due to the vasodillation of the retinal blood vessels which is accompanied by an increase in capillary permeability. That permits larger serum proteins to enter the cell, shifting the osmotic pressure at the capillary wall such that cell swelling takes place due to the entrance of water. Otherwhile, the repairing processes may be occurred due to that some intracellular substances are released and gradually diffused out of the cells and this would explain the latent period of several days. This could be similar to that occurred in sunburns (erytherma) as reported by Sliney and Wolbrast, 1979, /19/.

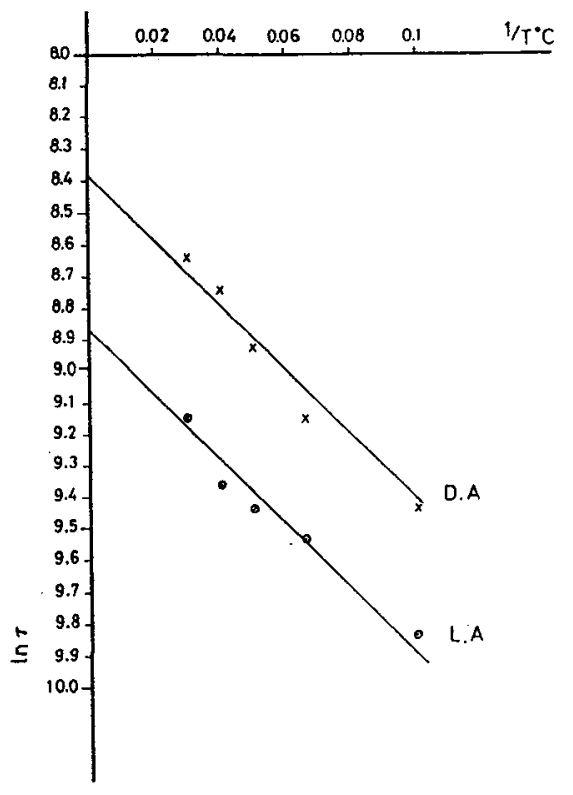

Fig.5. The relation between the natural logarithm of the relaxation time $(\ln \tau)$ and the reciprocal of temperature $1 / \mathrm{T}$ of light (L.A) and dark (D.A) adapted chicken eyes at normal condition.

The above mentioned discussion with our data obtained from the morphological studies on the chicken retina exposed to laser, with the same conditions stated before, were found very useful in constructing a simplified schematic model summarizes the possible mechanism of laser damage/repair processes, figure (6).

Finally, the results of the present work indicated that the dielectric measurements are very useful to detect the laser sensitivity of the eye, during laser treatments. Accordingly, we could define the best conditions for the laser application in order to reduce the critical damage/repair ratio. Such conditions are, the laser applications should be carried out in dark adapted eyes and at low temperature. 


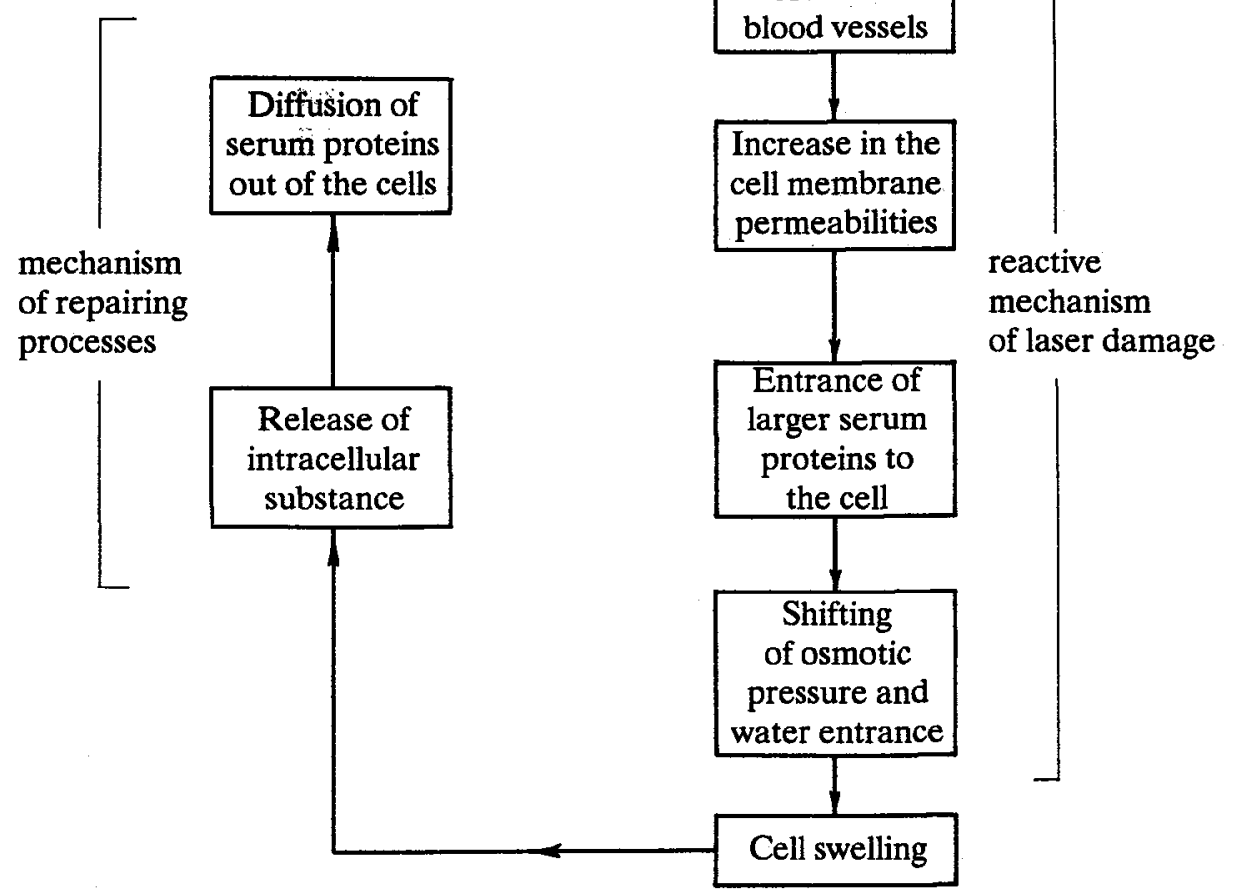

Fig.6. Schematic model summarizing the possible mechanism of Laser damage/repair processes.

\section{References.}

11. PETHIG,R, IEEE Trans. Elect. Insul. EI-19 (1984) 453.

12\% ONCLEY,J L, Proteins, Amino acids and Peptides, ed. Cohn and T Edsall (New York: Reinhold) (1943) 543.

13/. HAGGIS,G H, BUCHANAN,T J and HASTED,J B, Nature 167 (1951) 607.

14/. GRANT,E H, Ann. N Y Acad. Sci. 125 (1965) 418.

/5/. SCHWAN,H P, Ann. N Y Acad. Sci. 125 (1965a) 344.

/6/. KELL,D B and HARRIS,C M, Eur. Biophys. J. 12 (1985a) 181.

17/. ZIMMERMANN,U, Biochem. Biophys. Acta 694 (1982) 227.

18\% ARNOLD,W M, WENDT,B, ZIMMERMANN,U and KORENSTEIN,R, Biochem. Biophys. Acta 813 (1985) 117.

/9\%. FUHR,G, GIMSA,J and GLASER,R, Studia Biophys. 108 (1985) 149. 
/10\% FUHR,G, GLASER,R and HAGEDORN,R, Biophys. J. 49 (1986) 395).

/11/. BONE,S and PETHIG,R, Int. J. Quantum Chem. Quantum Biol. Symp. 10 (1983) 133.

112/. NEUMANN,E, Modern Bioelectrochemistry sd. Gutmann and H Keyzer (New York: Plenum) (1986) 97.

/13/. MORGAN,H and PETHIG,R, J. Chem. Soc. Faraday Trans. 182 (1986) 143.

/14/. SCHWAN,H P, Adv. Biol. Med. Phys. 5 (1957) 147.

15\%. KELL,D B, Collective Phenomena in Physics and Biophysics ed. T B Barret (New York: Plenum) (1986b).

16\% SCHWAN,H P, Physical Techniques in Biological Research Vol VIB, ed. W L Nastuk (New York: Academic) (1963) 323.

/17/. COLE,K S and COLE,R H, J. Chem. Phys. 9 (1941) 341.

18/. GLASSTONE,S, LAIDLER,K J and EYRING,H, The Theory of Rate Processes (New York: McGraw-Hill) (1941).

119\%. SLINEY,D and WOLBRASHT,M, Safety with Lasers and Other Optical Sources (New York and London: Plenum) (1979). 